\title{
Implementation Barriers to Augmented Reality Technology in Public Services
}

\author{
https://doi.org/10.3991/ijim.v15i13.22667 \\ Ruth S. Contreras-Espinosa $\left.{ }^{(}\right)$, Alejandro Blanco-M \\ University of Vic-Central University of Catalonia, Vic, Spain \\ ruth.contreras@uvic.cat \\ Jose Luis Eguia-Gomez \\ Polytechnic University of Catalonia, Barcelona, Spain
}

\begin{abstract}
Technology has become an essential element in today's digital life. The way users interact with different business services is changing thanks to Augmented Reality (AR), and the use of this technology in handhelds is gaining importance nowadays. Public and private organizations cannot be left behind, and they should strive to meet the demand for interactive services with AR. Through this review, we identified four potential major barriers to AR implementation, three of which were present in actual applications. We found that these barriers were similar across areas and that they were mainly related to the technology itself rather than to user interaction. For each of the barriers, we present a list of possible solutions or enablers that can help overcome the detected limitations.
\end{abstract}

Keywords - Augmented Reality, public services, barriers. smart city

\section{Introduction}

Technology has become an essential element in today's digital life. The way users interact with different business services is changing thanks to Augmented Reality (AR) [1], and the use of this technology in handhelds is gaining importance nowadays. Public and private organizations cannot be left behind, and they should strive to meet the demand for interactive services with AR [2].

AR is the technology that enables the superposition of virtual 3D objects in a real 3D environment. This is achieved thanks to devices equipped with a camera and a screen through which the citizen lives the immersive experience offered by the AR. This technology aims to enrich the real environment with virtual information, creating the opportunity to offer real-time and collaborative input from physical environments without the need to fill the physical environment with objects that may hinder interaction. AR has already been successfully applied in fields such as industrial design, education, healthcare, and psychology [3]. In addition, one of the current approaches to take advantage of the availability of information from smart cities thanks to the Internet 
of Things (IoT) is the implementation of AR to facilitate access to information services in real time [4].

In this paper, we first analyze the possible barriers found in the different fields where AR is widely deployed. Then, we propose several solutions (enablers) for the most common problems that challenge AR implementation.

\subsection{Methodology}

To examine this topic, we followed the steps indicated in [5], and conducted an author-based literature review as follows:

Topic/Questions reviewed: To investigate the different barriers that may emerge in AR approaches, we posed the following research questions: (RQ1) Which are the main barriers to the implementation of AR in public services? (RQ2) Can we propose similar solutions across areas? and (RQ3) Are the potential barriers described in the literature actually present in real applications?

Keyword search: We used the following key terms for this literature review: augmented reality + barriers + services.

Literature sources: Literature was gathered by searching in databases that compile academic documents, in this case, Google Scholar and ScienceDirect.

Background: To be able to differentiate between Mixed Reality (MR) and Augmented Reality (AR), we reviewed and included the definition of both concepts. The main fields in which AR has been successfully and widely deployed are also detailed in this section.

Literature selection: This review includes book chapters, scientific papers, conference proceedings or thesis published in an academic environment. The material was filtered by reviewing the article title and the keywords provided by the author, as well as their synonyms. The whole body of each paper (abstract and all the subsections) was analyzed in order to determine whether they referred to theoretical or practical applications.

\subsection{Background}

For the purposes of this study, it is crucial to differentiate between Augmented Reality (AR) and Mixed Reality (MR): AR enables users to explore a virtual representation of objects in a real-world environment in an interactive way: it takes the user's current real environment and merges it with 3D models of objects attached to the environment through AR markers [6]. AR requires the use of a camera, which captures the real world, and a screen through which the user visualizes the merged result. The device may include a set of complementary sensors to detect the geographical position and the orientation of the user. In addition, it may have onboard hardware with computing capabilities to perform the image processing required in case of including automatic AR-marker discovery mechanisms. On the other hand, MR goes a step further, taking Augmented Reality to another level where digital images projected onto the real world can be visualized and manipulated by the users thanks to a holographic projection and without requiring a screen [7]. 


\subsection{Common AR applications}

Medical: Pre-operative imaging and training is a field in which AR emerged as a technology. It provides a real-time visual interface to monitor the impact of an intervention on patients based on data from different sensors such as magnetic resonance imaging (MRI), thus reducing the risk of any operation. The first AR-assisted surgery was performed by [8], who superimposed a tomography during an intervention.

Military: The army is the field where the first implementations of AR arrived. HeadUp Displays (HUDs) and Head-Mount Displays (HMDs) are essential devices for soldiers to monitor orders and be aware of battlefield operations [9].

Tourism: AR is widely used in tourism, and it provides the advantage of having a personal guide to accompany guests at their convenience. One of the first known implementations, which included an on-site guide, is presented in [10].

Navigation: The implementation of massive AR in the navigation field dates to the 90 s, when the $3 \mathrm{G}$ network made it possible to download a reasonable volume of data in real time, allowing devices such as PDAs to display the necessary virtual information on the screen at any current position together with traffic indicators, such as speed, direction, or traffic service information [11]. Navigation has improved with the inclusion of HUDs on the front glass to display traffic and vehicle information.

Education: Education is one of the fields in which AR can be deployed with greater success due to the rapid and perfect adaptation of students to this new learning paradigm. Books can be replaced and improved by augmented content to explain information or visualize historical events, for instance. Game-like interactions could also improve academic performance [12].

Games: Games represent the most successful and profitable market for AR technology [13], almost doubling any other sector in terms of implementations. This translates into the game industry being the sector that invests most in AR innovation. The main difference between AR with respect to other competing technologies in games such as Virtual Reality (VR) is that AR expands the field of play to the physical world, enabling sports and exercise activities [14], as well as social interaction [15].

\subsection{Potential barriers}

It is a common assumption that technology comes at cost. The main potential barriers to AR implementation reported in the literature are discussed here. These four theoretical barriers are considered as the most important ones because they are difficult to overcome.

Privacy: A fully immersive AR experience is challenging in terms of user privacy due to the way users interact with the system and the type of data they must provide to enrich the experience, which may include user-specific set of habits and interaction patterns. Agencies need to address privacy issues with policies and security risk management [16].

Legacy systems: AR can help citizens, workers and general service users retrieve, process, and examine large amounts of data through an easy and interactive experience. 
Integration with legacy systems and platforms is a challenging task due to the lack of communication mechanisms [17].

Requirements: The definition of the project goals, requirements and resources is a challenging task for project officers [18]. Stakeholders must balance between cost, setup time, accuracy, and the type of required devices. These devices can be as simple as a smartphone with an accelerometer, or as elaborated as body sensors [19]. The visual interface in low-cost implementations is usually a smartphone, but it can be as complex and expensive as a robot-control helmet or a military-pilot helmet (AHMD) [20].

Financial: The financial sustainability of AR applications can be an issue in certain cases. Some projects implement AR technology to add value to their products and increase revenues, either because this leads to more efficiency in task performance, or because this raises the quality of the service [21]. In the case of public services, justifying the use of AR can be a challenge, since increased revenues cannot be used as a measure.

\section{Results / Literature Review}

Navigation, geographical information:[4] described an AR application that enables the citizens of Castellón to locate specific public service buildings with a smartphone by visualizing the overlapped information on the screen. This app shows 3D markers with additional information at the building's exact location, as compared to the 2D information that Google Maps or other services provide. The authors indicate that the app uses GIS as a source of geographical data. We identified the so-called "occlusion problem" as a major barrier, which is described as displaying multiple overlapping AR objects covering the critical information for the user, so it hinders correct visualization. To overcome this issue, we suggest the use of lists or giving the user the option to adjust the size of the markers.

The geoSmartCity described in [22] is another geolocalized AR implementation in which the authors claim that ICTs have revolutionized the way citizens interact with the urban environment. This work analyzed different implementations and their tools, and compared the application with the state of the art. The authors determined that outdated geographical data represents an important barrier because the AR implementation depends on the Geo-Markers. Administrative regulations seem to constitute another major barrier, as technology changes faster than regulatory frameworks.

[23] presented an innovative interface for technicians with real-time information to repair, configure and locate any device of the smart city infrastructure. Since the ecosystem of IoT devices is diverse, this tool provides a faster way to locate small sensors and actuators placed around the city. The authors indicated that the AR interface of this tool is useful when the intervention requires travel to distant locations, but it represents a barrier when technicians arrive at the target site, because they may encounter problems locating the devices that require repair due to the inconsistency of the position of AR anchors as a consequence of the fluctuations in the GPS. Technicians also reported inaccuracies in AR anchors by image recognition due to poor illumination. 
City planning: The application described in [24] includes information on what is being built by the citizens in the neighborhood. The authors highlighted data access as a barrier because data exchange is what powers smart cities, particularly, the access to automated services to download large amounts of data like APIs. Missing format specification, or poor data quality such as missing data, produces non-geolocalized markers, which constitutes another major limitation.

[25] presented a project based on geolocalization and examined its advantages and limitations to determine the usability and potential contribution of the AR application to the city services. The authors detected four major barriers, but for the purposes of this review we will comment on the two most relevant ones from our point of view. The first one refers to geolocalization accuracy, which was not as good as expected due to signal inaccuracies and the GPS antenna. Some of the geolocalization-based tools examined generated "floating" objects due to position inaccuracies. The second major issue was element visualization. The authors indicated that it may be necessary to preselect which type of elements are displayed, because in small screens the user experience (UX) may be compromised due to object overcrowding and deficient visualization.

Others have created useful tools for the community by providing an interface to visualize which buildings will be built and how the neighborhood will look like, such as the case described in [26]. The authors highlighted that using AR to visualize the result of a building, collecting citizen feedback and evaluating its impact, is more costeffective than gathering feedback after a building is completed. AR visualization also provides a better idea of the final dimensions as compared to scaled prototypes. The authors detected some barriers in relation to connectivity. Due to the low signal power and limited bandwidth to download the necessary 3D objects and related information, the content is drawn with a delay that prevents a real-time experience. A secondary problem is caused by improper geolocalization due to poor GPS reception in indoor or covered areas.

[27] studied the different barriers present in relation to the construction field applications, and despite the authors discovered four limitations, we will consider only the three that are relevant for the purposes of this study. The first one corresponds to the difficulty of getting the required data to display the 3D models and the additional textual information due to the low-signal and connection speed typical from the environment where the application is used. The second issue is due to the low accuracy of the mechanism used to identify the sites and objects, which creates a misalignment between the obtained and the real positions. Finally, the third barrier refers to hardware limitations and the use of low-power devices, which may slow down image processing and visualization refresh.

In their study, [28] discussed the implementation of AR to visualize 3D objects in parks. The aim of this application was to show to the elderly which new items would be included in the parks in their neighborhood. These items included benches, lamp posts, biking lanes, noise-cancelling devices, furniture, etc. The main barrier identified is related to object viewing, as dark-colored objects in dark places made visualization more challenging. In addition, the use of holograms for MR was not effective in daylight due to the device employed (HTC headset). 
Health: AR technology is also used to improve the quality of life of disabled citizens. [29] studied the use of a prototype based on RFID and AR to enable citizens with motor disabilities (in a wheelchair) to visualize and obtain information about products beyond their physical reach. In this case, one significant barrier seemed to be the ergonomics, because a tablet device was employed and the users were unable to move while maintaining the device in the same position. Additionally, some of the users highlighted the difficulty to see the product details because the screen was too small.

Smart city services: [30] created an AR application for public transport in Serbia through which citizens could get information about arrival times, and bus and touristic routes by means of geolocalization and image recognition. The information was provided thanks to the IoT infrastructure integrated in the vehicles and in the city facilities. The authors realized that, as the user provides sensible information such as real-time position, their identification (name), and the history of travels, a security layer had to be included, which became a major barrier to AR integration with the IoT infrastructure. Data privacy should thus be considered at all service design levels and steps to prevent future problems in case of data breaches.

AR applications can add value to tourism services, as described in [31]. The authors developed a prototype that collects information, such as points of interest and their description, and then processes and merges the data with additional sourced information. The biggest barrier found is that homogenizing such heterogeneous data properties like time scales, units, names, and information protocols, becomes a complex and time-consuming task for the service developer.

[32] Analyzed four types of interaction with a public display where citizens could publish and read information. Three of the interaction modes were non-AR and provided a low-privacy level, while the last one, based on AR, provided a higher level of privacy and allowed multiple users to interact simultaneously with the public display. Although the provided content might have been limited to a group of people, the authors indicated that an issue that arose was "shoulder surfing", when a person in the proximity can visualize private information while the user is clicking on the point of interest (POI).

Lastly, [33] described the SmartSantander project as a holistic platform that integrates several services of the municipality of Santander, in Spain. The application combines different ICT platforms with several IoT devices distributed all over the city center. The user interface (mobile phones) displays the transport routes, timing, geographical position of the different services, important information indicated by other users, and is used as a sensor device, providing information on the traffic, and user position and habits. The authors detected several barriers in the implementation. As they indicated, the interface was somehow complex and required training, and thus, baseline user skills should not be ignored. They also pointed out data privacy as being problematic because of the shared information and the interactions. Given that information is stored, there is always a potential risk of data breaches.

Education: In the educational field, [34] conducted a study from the teacher perspective on an AR application for teaching purposes. The author evaluated what prevents AR to land as a common technology on schools, as several previous studies determined that students present positive AR integration [35] [36]. After interviewing 
the teachers, the conclusion was that the main barriers were the lack of support in terms of infrastructure and resources (visualization devices and the required licenses), and the lack of AR training programs for senior teachers.

\section{Discussion and Conclusion}

Through this literature review, we identified several common factors or barriers that lead to a deficient experience or that limit the evolution of AR in the fields under study, and we grouped them into nine different categories, as shown in Table 1.

Table 1. Relation of proposed solutions to the different barriers to AR implementation.

\begin{tabular}{|c|c|c|c|c|}
\hline Author & Field & Category & Barrier description & Proposed enabler \\
\hline$[4]$ & $\begin{array}{l}\text { POI } \\
\text { navigation }\end{array}$ & Visualization & Overcrowded visualization & $\begin{array}{l}\text { Option to filter by } \\
\text { layer/category/size [37] }\end{array}$ \\
\hline \multirow{4}{*}[22]{} & \multirow[b]{2}{*}{$\begin{array}{l}\text { POI } \\
\text { navigation }\end{array}$} & Geolocation & $\begin{array}{l}\text { Outdated geographical } \\
\text { information }\end{array}$ & Crowdsourcing updates [38] \\
\hline & & Regulations & $\begin{array}{l}\text { Inability to access other } \\
\text { services or display some } \\
\text { information due to local } \\
\text { regulations }\end{array}$ & $\begin{array}{l}\text { Create new administrative } \\
\text { processes to enable AR adoption } \\
\text { with an evaluation commission } \\
{[39]}\end{array}$ \\
\hline & \multirow[b]{2}{*}{$\begin{array}{l}\text { POI } \\
\text { navigation }\end{array}$} & Geolocation & $\begin{array}{l}\text { Inconsistent AR anchor } \\
\text { position across devices due to } \\
\text { GPS sensor inaccuracy }\end{array}$ & $\begin{array}{l}\text { Implement the usage of near-field } \\
\text { localization based on RFID indoors } \\
\text { [40] [41], or AR indoor navigation } \\
\text { systems [42] }\end{array}$ \\
\hline & & $\begin{array}{l}\text { AR anchor } \\
\text { identification }\end{array}$ & $\begin{array}{l}\text { Issues with AR anchor } \\
\text { localization based on image } \\
\text { processing: the system cannot } \\
\text { detect the stored base } \\
\text { environment on which the AR } \\
\text { anchor was set }\end{array}$ & $\begin{array}{l}\text { Improve object tracking in multiple } \\
\text { illumination conditions [43], or add } \\
\text { image preprocessing [44] }\end{array}$ \\
\hline$[24]$ & City planning & Data & $\begin{array}{l}\text { Access to data, missing fields, } \\
\text { and different format or scales }\end{array}$ & $\begin{array}{l}\text { Implement standard data protocols } \\
\text { in an open data API service [45] }\end{array}$ \\
\hline \multirow[t]{2}{*}[25]{} & \multirow{2}{*}{ City planning } & Geolocation & \begin{tabular}{|l|} 
GPS position inaccuracy, \\
floating objects due to \\
inconsistent sensor information
\end{tabular} & $\begin{array}{l}\text { Better GPS devices, usage of near- } \\
\text { field localization based on RFID } \\
\text { indoors [40] [41], or AR indoor } \\
\text { navigation systems [42] }\end{array}$ \\
\hline & & Visualization & $\begin{array}{l}\text { Element visualization (relative } \\
\text { scales), overlapping, and } \\
\text { overcrowded areas with } \\
\text { numerous AR markers }\end{array}$ & $\begin{array}{l}\text { Improve UX through context } \\
\text { filtering or facilitating visualization } \\
\text { of relevant information [46] }\end{array}$ \\
\hline \multirow[t]{2}{*}[26]{} & \multirow{2}{*}{ City planning } & Connection & $\begin{array}{l}\text { Connection problems, low } \\
\text { signal in some places, slow } \\
\text { download }\end{array}$ & $\begin{array}{l}\text { Pre-download large-information } \\
\text { objects, caching information } \\
\text { mechanisms [47] }\end{array}$ \\
\hline & & Geolocation & \begin{tabular}{|l|} 
GPS position inaccuracy, \\
floating objects due to \\
inconsistent sensor information
\end{tabular} & $\begin{array}{l}\text { Better GPS devices, usage of near- } \\
\text { field localization based on RFID } \\
\text { [40] [41] }\end{array}$ \\
\hline [28] & City planning & Visualization & $\begin{array}{l}\text { Visualization of objects, color, } \\
\text { contrast }\end{array}$ & $\begin{array}{l}\text { Include a preprocessing mechanism } \\
\text { to compare environmental lighting } \\
\text { design to recalculate the 3D-model } \\
\text { contrast and color based on the } \\
\text { background light [43] }\end{array}$ \\
\hline
\end{tabular}




\begin{tabular}{|c|c|c|c|c|}
\hline & & & $\begin{array}{l}\text { Using hologram technology in } \\
\text { daylight }\end{array}$ & $\begin{array}{l}\text { Only use holograms in low light } \\
\text { conditions. Due to the limitations } \\
\text { of the current technology [48], it is } \\
\text { not feasible to produce the number } \\
\text { of nits required for direct sunlight }\end{array}$ \\
\hline \multirow{2}{*}{ [29] } & \multirow[b]{2}{*}{ Healthcare } & Interaction & $\begin{array}{l}\text { Problems for users handling } \\
\text { big visualization devices, } \\
\text { which cannot use their hands } \\
\text { for any other purpose }\end{array}$ & $\begin{array}{l}\text { Provide a portable support system } \\
\text { or use smaller devices like AR } \\
\text { glasses [49] }\end{array}$ \\
\hline & & Visualization & $\begin{array}{l}\text { Visualization requires correct } \\
\text { pointing, angle, and position } \\
\text { towards the AR elements }\end{array}$ & $\begin{array}{l}\text { Include environment capture } \\
\text { features so that the user can freeze } \\
\text { the object position. Provide a better } \\
\text { interface with selectable scales or } \\
\text { bigger screen interfaces [50] }\end{array}$ \\
\hline [30] & $\begin{array}{l}\text { Smart city } \\
\text { services }\end{array}$ & Privacy & $\begin{array}{l}\text { Balance between user } \\
\text { interactivity and } \\
\text { personalization is required to } \\
\text { improve the services that rely } \\
\text { on user privacy issues }\end{array}$ & $\begin{array}{l}\text { Inform the user about what } \\
\text { personal data is used and what type } \\
\text { of processing is performed [51]. } \\
\text { Consider user privacy during } \\
\text { service design, which means } \\
\text { delegating data storage and } \\
\text { management to a certified service } \\
\text { [52] }\end{array}$ \\
\hline [31] & $\begin{array}{l}\text { Smart city } \\
\text { services }\end{array}$ & Data & $\begin{array}{l}\text { Heterogenous source of data, } \\
\text { different formats, scales, time } \\
\text { ranges, units, and data- } \\
\text { gathering mechanisms }\end{array}$ & $\begin{array}{l}\text { Create a parallel project with a self- } \\
\text { configurable API which can } \\
\text { transform the input format to a } \\
\text { standard format. Other applications } \\
\text { to exchange information can use } \\
\text { this API. Another option is to ask } \\
\text { the data providers to integrate open } \\
\text { data protocols [45] }\end{array}$ \\
\hline [32] & $\begin{array}{l}\text { Smart city } \\
\text { services }\end{array}$ & Privacy & $\begin{array}{l}\text { Privacy issues while the user is } \\
\text { interacting with the AR marker } \\
\text { in public and providing } \\
\text { sensible personal information, } \\
\text { like username access }\end{array}$ & $\begin{array}{l}\text { Enable the user to freeze the } \\
\text { position and the AR marker they } \\
\text { are pointing at, making it possible } \\
\text { to physically move to another place } \\
\text { with better privacy to exchange } \\
\text { information [50] }\end{array}$ \\
\hline \multirow[b]{2}{*}{ [33] } & \multirow[b]{2}{*}{$\begin{array}{l}\text { Smart city } \\
\text { services }\end{array}$} & Interaction & $\begin{array}{l}\text { Complex interfaces with lots of } \\
\text { options due to the holistic } \\
\text { approach }\end{array}$ & $\begin{array}{l}\text { Design a context-aware interface: } \\
\text { AR markers and available } \\
\text { information should be related to } \\
\text { what the user is looking for [46] }\end{array}$ \\
\hline & & Privacy & $\begin{array}{l}\text { Data privacy issues, due to the } \\
\text { required storage of user routes, } \\
\text { location, and habits }\end{array}$ & $\begin{array}{l}\text { Inform the user about what } \\
\text { personal data is used and what type } \\
\text { of processing is performed [51]. } \\
\text { Delegate data storage and } \\
\text { management to a certified service } \\
\text { [52] }\end{array}$ \\
\hline \multirow[t]{2}{*}{ [34] } & \multirow[t]{2}{*}{ Education } & Resources & $\begin{array}{l}\text { Limitations in the available } \\
\text { infrastructure to provide AR } \\
\text { interfaces, devices, and licenses }\end{array}$ & $\begin{array}{l}\text { AR sessions could be organized as } \\
\text { an additional rotating lecture, } \\
\text { shared among different teachers, } \\
\text { like the first personal computer's } \\
\text { introduction at schools with fewer } \\
\text { resources }\end{array}$ \\
\hline & & Interaction & $\begin{array}{l}\text { Lack of knowledge to manage } \\
\text { and interact with AR }\end{array}$ & $\begin{array}{l}\text { Provide specific AR training } \\
\text { seminars for teachers [53] }\end{array}$ \\
\hline
\end{tabular}


GPS devices provide user position with a certain degree of accuracy, but this accuracy does not seem to be enough to prevent errors in the localization of small objects. To solve this issue, we suggest the use of RFID localization [40] [41]. This technology employs near-field emitters or proximity protocol beacons, such as Bluetooth or NFC. According to the works reviewed, the use of RFID devices is required indoors, since GPS systems do not perform well inside buildings, even when an improved system employing phone networks is implemented [54]. Another option is using shape or scene/environmental recognition (indoor navigation systems) [42], although this technology experiments the same issues as the anchoring of virtual elements to reality. Despite devices count with several types of sensors to anchor or detect the scene (such as accelerometers), cameras are the crucial tool for this purpose. Cameras capture the images and a computer vision software processes them enabling the identification of shapes and surfaces where the AR objects can be anchored, as well as recovering previously assigned objects. These images suffer variations in relation to illumination and focus, which can prevent the device from correctly recognizing the real shape of objects or surfaces and, therefore, from identifying them. To overcome these issues, we suggest including image preprocessing methods to improve illumination [43]. Overall, indoor localization issues were the most common barriers according to the literature, which answers RQ1 (Which are the main barriers to the implementation of AR in public services?).

User experience and visualization may also be affected by factors which are not related to the AR technology itself, but to the interface chosen by the developers or required by design. Several authors mention that, often, AR information is displayed in a way that makes it challenging for users to perceive it or treat it. This is normally due to a lack of adjustment of the size, illumination, and position of the AR model in relation to the point [37]. Therefore, it is important to use UX strategies [46] to help identify which features to include in the interface to present the information to the users in a way that facilitates adjusting and filtering the elements to reach the useful content they wish to visualize. Shadow adjustment to highlight or blend the 3D model seems to be a good starting point to enhance visualization [43]. On the other hand, the use of AR technology over holographic devices is discouraged outdoors, since the MEMS panels where the images are projected do not produce enough luminous intensity (nits) and cannot render visible elements under the sunlight. Holographic devices are especially cost-effective in indoor implementations where light conditions are low.

Finally, there is a group of barriers that respond to factors which are external to AR technology, such as privacy, resources, training, and data access issues. Privacy issues are of relevance when AR device interaction takes place in public environments where users can both provide and visualize information. Applications in which users provide information by adding models or content require privacy control and user notification mechanisms [51]. When AR applications employ external resources, conversion issues that affect model or geographical information formats may arise. This is very typical in the field of user-enriched maps through crowdsourcing, where AR is being widely implemented. The standardization of the different sources of data becomes a barrier even for tool developers, which often end up displaying incorrect information in terms of size or position, even when this could be easily fixed [45]. In the educational field, 
barriers in AR technology implementation mainly refer to lack of training on the use of these tools among teachers or limited access to specialized devices. Training is an essential element to prevent usage abandonment [53].

During this review, we found similar solutions that can be applied to different areas, which positively answers RQ2 (Can we propose similar solutions across different areas?). Solutions to technical barriers can be categorized into three groups: user localization, anchoring AR elements to reality, and scene/object recognition.

We detected barriers linked to legacy systems, which are those that provide information to AR interfaces, as well as barriers related to device requirements (lowlight conditions, image processing) and, to a lesser extent, privacy-related issues. Therefore, at least three of the four potential barriers described in the literature clearly emerged in the different applications (being financial issues the exception), which partially answers RQ3 (Are the potential barriers described in the literature actually present in real applications?).

In this paper, we first established the basic definitory concepts of Augmented Reality and Mixed Reality in order to determine which applications corresponded to each of these technologies. We then explored the most important fields in which we found a great body of literature on AR work and identified four potential barriers to AR implementation. To confirm whether these barriers existed in citizen services applications, we conducted an author-based literature review and produced a classification of works and their corresponding barriers, to which we proposed a list of solutions (enablers). This classification highlights that there is a certain similarity among barriers regardless of the target users or the institutions that implement AR technology, and that these rather respond to technological issues.

\section{References}

[1] M. E. Porter and J. E. Heppelmann, "Why every organization needs an augmented reality strategy," HBR'S 10 MUST, p. 85, 2017.

[2] M. Noghabaei, A. Heydarian, V. Balali and K. Han, "Trend Analysis on Adoption of Virtual and Augmented Reality in the Architecture, Engineering, and Construction Industry," Data, vol. 5, 2020. https://doi.org/10.20944/preprints201912.0369.v1

[3] N. A. Rani, F. A. Aziz, A. A. Hairuddin, S. A. Ahmad and A. R. Hemdi, "Augmented reality: capabilities and challenges in machining industry aligned with industry 4.0," Advances in Materials and Processing Technologies, vol. 0, pp. 1-9, 2020.https://doi.org/10.1080/2374 068x.2020.1793269

[4] F. Ramos, S. Trilles, J. Torres-Sospedra and F. J. Perales, "New Trends in Using Augmented Reality Apps for Smart City Contexts," ISPRS International Journal of Geo-Information, vol. 7, 2018. https://doi.org/10.3390/ijgi7120478

[5] J. Webster and R. T. Watson, "Analyzing the Past to Prepare for the Future: Writing a Literature Review," MIS Quarterly, vol. 26, p. xiii-xxiii, 2002.

[6] S. Zlatanova, "Augmented Reality Technology," GISt Report No. 17, Delft, 2002, 72 p., 12 2002.

[7] J. W. Goodman, "An introduction to the principles and applications of holography," Proceedings of the IEEE, vol. 59, pp. 1292-1304, 1971. 
[8] D. W. Roberts, J. W. Strohbehn, J. F. Hatch, W. Murray and H. Kettenberger, "A frameless stereotaxic integration of computerized tomographic imaging and the operating microscope," Journal of Neurosurgery, vol. 65, pp. 545-549, 1986. https://doi.org/10.3171/ ins.1986.65.4.0545

[9] [9] M. A. Livingston, Z. Ai, K. Karsch and G. O. Gibson, "User interface design for military AR applications," Virtual Reality, vol. 15, p. 175-184, 2011. https://doi.org/10.1007/ s10055-010-0179-1

[10] V. Vlahakis, J. Karigiannis, M. Tsotros, M. Gounaris, L. Almeida, D. Stricker, T. Gleue, I. Christou and N. Ioannidis, "ARCHEOGUIDE: first results of an augmented reality, mobile computing system in cultural heritage sites," 2001. https://doi.org/10.1145/584993.585015

[11] Z. Hu and K. Uchimura, "Dynamical-road modeling and matching for direct visual navigation," in Sixth IEEE Workshop on Applications of Computer Vision, 2002. (WACV 2002). Proceedings., 2002. https://doi.org/10.1109/acv.2002.1182188

[12] D. Fonseca, N. Martí, E. Redondo, I. Navarro and A. Sánchez, "Relationship between student profile, tool use, participation, and academic performance with the use of Augmented Reality technology for visualized architecture models," Computers in Human Behavior, vol. 31, pp. 434-445, 2014. https://doi.org/10.1016/j.chb.2013.03. 006

[13] G. Sachs, "Virtual \& augmented reality: Understanding the race for the next computing platform," Equity research, vol. 13, 2016.

[14] H. Zhao, H. Chen, J. Wang and R. Zhang, "Augmented Reality Game Development and Experience Based on Intelligent Mobile Phone," in Transactions on Edutainment XII, Springer, 2016, p. 38-47. https://doi.org/10.1007/978-3-662-50544-1_3

[15] L. Almeida, P. Menezes and J. Dias, "Augmented reality framework for the socialization between elderly people," in Handbook of Research on ICTs for Human-Centered Healthcare and Social Care Services, IGI Global, 2013, p. 430-448. https://doi.org/10.4018/978-14666-3986-7.ch023

[16] K. Lebeck, K. Ruth, T. Kohno and F. Roesner, "Towards Security and Privacy for Multiuser Augmented Reality: Foundations with End Users," in 2018 IEEE Symposium on Security and Privacy (SP), 2018. https://doi.org/10.1109/sp.2018.00051

[17] L. Wing, "Barriers to e-government integration," Journal of Enterprise Information Management, vol. 18, pp. 511-530, 0112005.

[18] M. Quandt, B. Knoke, C. Gorldt, M. Freitag and K.-D. Thoben, "General Requirements for Industrial Augmented Reality Applications," Procedia CIRP, vol. 72, pp. 1130-1135, 2018. https://doi.org/10.1016/j.procir.2018.03.061

[19] Xun Luo and T. Kline and H. C. Fischer and K. A. Stubblefield and R. V. Kenyon and D. G. Kamper, "Integration of Augmented Reality and Assistive Devices for Post-Stroke Hand Opening Rehabilitation," in 2005 IEEE Engineering in Medicine and Biology 27th Annual Conference, 2005. https://doi.org/10.1109/iembs.2005. 1616080

[20] A. Sisodia, M. Bayer, P. Townley-Smith, B. Nash, J. Little, W. Cassarly and A. Gupta, "Advanced Helmet Mounted Display (AHMD)," in Head- and Helmet-Mounted Displays XII: Design and Applications, 2007. https://doi.org/10.1117/12.723765

[21] E. E. Cranmer, M. C. tom dieck and T. Jung, "How can Tourist Attractions Profit from Augmented Reality?" in Augmented Reality and Virtual Reality: Empowering Human, Place and Business, T. Jung and M. C. tom dieck, Eds., Cham, Springer International Publishing, 2018, pp. 21-32. https://doi.org/10.1007/978-3-319-64027-3_2

[22] S. Daniel and M.-A. Doran, "GeoSmartCity: Geomatics Contribution to the Smart City," in Proceedings of the 14th Annual International Conference on Digital Government Research, New York, NY, USA, 2013. https://doi.org/10.1145/2479724. 2479738 
[23] D. Chaves-Diéguez, A. Pellitero-Rivero, D. García-Coego, F. J. González-Castaño, P. S. Rodríguez-Hernández, Ó. Piñeiro-Gómez, F. Gil-Castiñeira and E. Costa-Montenegro, "Providing IoT services in smart cities through dynamic augmented reality markers," Sensors, vol. 15, p. 16083-16104, 2015. https://doi.org/10.3390/s150716083

[24] S. Vert and R. Vasiu, "Augmented Reality Lenses for Smart City Data: The Case of Building Permits," in Recent Advances in Information Systems and Technologies, Cham, 2017. https://doi.org/10.1007/978-3-319-56535-4_53

[25] M. Schrenk, V. Popovich, P. Zeile, B. Allbach, M. Memmel and B. Streich, "Mobile Augmented City-New Methods for Urban Analysis and Urban Design Processes by using Mobile Augmented Reality Services," 12011.

[26] D. Broschart, P. Zeile and B. Streich, "Augmented Reality as a Communication Tool in Urban Design Processes," 2013.

[27] A. Fenais, N. Smilovsky, S. T. Ariaratnam and S. K. Ayer, "A Meta-Analysis of Augmented Reality Challenges in the Underground Utility Construction Industry," in Construction Research Congress 2018, 2018, pp. 80-89. https://doi.org/10.1061/9780784481295.009

[28] A. S. Williams, C. Angelini, M. Kress, E. Ramos Vieira, N. D'Souza, N. D. Rishe, J. Medina, E. Özer and F. Ortega, "Augmented Reality for City Planning," in Virtual, Augmented and Mixed Reality. Design and Interaction, Cham, 2020. https://doi.org/10.1007/978-3-03049695-1_17

[29] Z. Rashid, J. Melià-Seguí, R. Pous and E. Peig, "Using Augmented Reality and Internet of Things to improve accessibility of people with motor disabilities in the context of Smart Cities," Future Generation Computer Systems, vol. 76, pp. 248-261, 2017. https://doi.org/ 10.1016/j.future.2016.11.030

[30] B. Pokrić, S. Krčo and M. Pokrić, "Augmented Reality Based Smart City Services Using Secure IoT Infrastructure," in 2014 28th International Conference on Advanced Information Networking and Applications Workshops, 2014. https://doi.org/10.1109/waina.2014.127

[31] S. Vert and R. Vasiu, "Integrating linked open data in mobile augmented reality applications - a case study," TEM Journal of Technology, Education, Management, Informatics, vol. Volume 4, pp. 35-43, 22015.

[32] C. Parker, M. Tomitsch, J. Kay and M. Baldauf, "Keeping It Private: An Augmented Reality Approach to Citizen Participation with Public Displays," in Adjunct Proceedings of the 2015 ACM International Joint Conference on Pervasive and Ubiquitous Computing and Proceedings of the 2015 ACM International Symposium on Wearable Computers, New York, NY, USA, 2015. https://doi.org/10.1145/2800835. 2804401

[33] V. Gutiérrez, J. A. Galache, L. Sánchez, L. Muñoz, J. M. Hernández-Muñoz, J. Fernandes and M. Presser, "SmartSantander: Internet of Things Research and Innovation through Citizen Participation," in The Future Internet, Berlin, 2013. https://doi.org/10.1007/978-3642-38082-2_15

[34] M. Alkhattabi, "Augmented Reality as E-learning Tool in Primary Schools' Education: Barriers to Teachers' Adoption," International Journal of Emerging Technologies in Learning (iJET), vol. 12, p. 91, 2 2017. https://doi.org/10.3991/ijet. v12i02.6158

[35] [35] J. Cabero-Almenara, J. M. Fernández-Batanero and J. Barroso-Osuna, "Adoption of augmented reality technology by university students," Heliyon, vol. 5, p. e01597, 2019. https://doi.org/10.1016/j.heliyon.2019.e01597

[36] H.-Y. Wang, H. B.-L. Duh, N. Li, T.-J. Lin and C.-C. Tsai, "An Investigation of University Students' Collaborative Inquiry Learning Behaviors in an Augmented Reality Simulation and a Traditional Simulation," Journal of Science Education and Technology, vol. 23, pp. 682-691, 0110 2014. https://doi.org/10.1007/s10956-014-9494-8 
[37] T. Olsson, E. Lagerstam, T. Kärkkäinen and K. Väänänen-Vainio-Mattila, "Expected user experience of mobile augmented reality services: a user study in the context of shopping centres," Personal and Ubiquitous Computing, vol. 17, pp. 287-304, 0122013. https://doi.org/10.1007/s00779-011-0494-x

[38] S. Osawa, R. Tanaka, T. Narumi, T. Tanikawa and M. Hirose, "Crowd-Cloud Window to the Past: Constructing a Photo Database for On-Site AR Exhibitions by Crowdsourcing," in Human Interface and the Management of Information: Applications and Services, Cham, 2016. https://doi.org/10.1007/978-3-319-40397-7_30

[39] J. B. Wiener, "The regulation of technology, and the technology of regulation," Technology in Society, vol. 26, pp. 483-500, 2004.

[40] M. Kourogi, N. Sakata, T. Okuma and T. Kurata, "Indoor/Outdoor Pedestrian Navigation with an Embedded GPS/RFID/Self-contained Sensor System," in Advances in Artificial Reality and Tele-Existence, Berlin, 2006.https://doi.org/10.1007/11941354_136

[41] A. R. J. Ruiz, F. S. Granja, J. C. P. Honorato and J. I. G. Rosas, "Accurate Pedestrian Indoor Navigation by Tightly Coupling Foot-Mounted IMU and RFID Measurements," IEEE Transactions on Instrumentation and Measurement, vol. 61, pp. 178-189, 2012. https://doi.org/10.1109/tim.2011.2159317

[42] K. Liu, G. Motta and T. Ma, "XYZ Indoor Navigation through Augmented Reality: A Research in Progress," in 2016 IEEE International Conference on Services Computing (SCC), 2016. https://doi.org/10.1109/scc.2016.46

[43] S. Blanco-Pons, B. Carrión-Ruiz, M. Duong, J. Chartrand, S. Fai and J. L. Lerma, "Augmented Reality Markerless Multi-Image Outdoor Tracking System for the Historical Buildings on Parliament Hill," Sustainability, vol. 11, 2019. https://doi.org/10.3390/ $\underline{\mathrm{su} 11164268}$

[44] K.-M. Koo and E.-Y. Cha, "Image recognition performance enhancements using image normalization," Human-centric Computing and Information Sciences, vol. 7, p. 33, 1911 2017. https://doi.org/10.1186/s13673-017-0114-5

[45] A. Degbelo, D. Bhattacharya, S. Trilles, C. Granell Canut, C. Kray and N. Schiestel, "Designing a Semantic API for Open City Data," JeDEM - eJournal of eDemocracy and Open Government, vol. 8, pp. 21-58, 12 2016. https://doi.org/10.29379/jedem.v8i2.420

[46] S. Irshad and D. R. Awang Rambli, "Multi-Layered Mobile Augmented Reality Framework for Positive User Experience," in Proceedings of the 2nd International Conference in HCI and UX Indonesia 2016, New York, NY, USA, 2016. https://doi.org/10.1145/2898459. $\underline{2898462}$

[47] S. Zehtabian, S. Khodadadeh, L. Bölöni and D. Turgut, "Modeling an intelligent controller for predictive caching in AR/VR-enabled home scenarios," Pervasive and Mobile Computing, vol. 71, p. 101334, 2021. https://doi.org/10.1016/j.pmcj.2021. 101334

[48] Y. Pan, J. Liu, X. Li and Y. Wang, "A Review of Dynamic Holographic Three-Dimensional Display: Algorithms, Devices, and Systems," IEEE Transactions on Industrial Informatics, vol. 12, pp. 1599-1610, 2016. https://doi.org/10.1109/tii. 2015.2496304

[49] A. Syberfeldt, O. Danielsson and P. Gustavsson, "Augmented Reality Smart Glasses in the Smart Factory: Product Evaluation Guidelines and Review of Available Products," IEEE Access, vol. 5, pp. 9118-9130, 2017. https://doi.org/10.1109/access. 2017.2703952

[50] H. Arshad, S. A. Chowdhury, L. M. Chun, B. Parhizkar and W. K. Obeidy, "A freeze-object interaction technique for handheld augmented reality systems," Multimedia Tools and Applications, vol. 75, pp. 5819-5839, 015 2016. https://doi.org/10.1007/s11042-015-2543$\underline{3}$

[51] A. Kotsios, "Privacy in an augmented reality," International Journal of Law and Information Technology, vol. 23, pp. 157-185, 32015. 
[52] C. Perera, C. McCormick, A. K. Bandara, B. A. Price and B. Nuseibeh, "Privacy-by-Design Framework for Assessing Internet of Things Applications and Platforms," in Proceedings of the 6th International Conference on the Internet of Things, New York, NY, USA, 2016. https://doi.org/10.1145/2991561.2991566

[53] J. M. Sáez-López, R. Cózar-Gutiérrez, J. A. González-Calero and C. J. Gómez Carrasco, "Augmented Reality in Higher Education: An Evaluation Program in Initial Teacher Training," Education Sciences, vol. 10, 2020. https://doi.org/10.3390/educsci10020026

[54] C. M. Takenga, Q. Wen and K. Kyamakya, "On the Accuracy Improvement Issues in GSM Location Fingerprinting," in IEEE Vehicular Technology Conference, 2006. https://doi.org/10.1109/vtcf.2006.580

\section{$5 \quad$ Authors}

Ruth S. Contreras-Espinosa is a researcher in Department of Communication, University of Vic-Central University of Catalonia, Vic, Barcelona, Spain. Email: ruth.contreras@uvic.cat

Alejandro Blanco-M currently works at the Department of Communication, University of Vic. Alejandro does research in Information Science, Distributed Computing and Data Mining. Their most recent publication is 'Identifying Health Status of Wind Turbines by Using Self Organizing Maps and Interpretation-Oriented PostProcessing Tools'.

Jose Luis Eguia-Gomez is a Professor (Associate) in Department of Engineering Design (PE), Polytechnic University of Catalonia, Barcelona, Spain.

Article submitted 2021-03-18. Resubmitted 2021-04-30. Final acceptance 2021-04-30. Final version published as submitted by the authors. 